\title{
A study of Psychiatric Consequences following Road Traffic accidents
}

\author{
Rawal N1', Thapa P2 , Bista $Y^{3}$ \\ ${ }^{1}$ Dr Namrata Rawal, Consultant Neuropsychiatrist, ${ }^{2}$ Dr Praswas Thapa, C onsultant Neuropsychiatrist, ${ }^{3}$ Dr \\ Yadav Bista, Head of Dept, Department of Neuropsychiatry, Shree Birendra Hospital, Kathmandu, Nepal
}

\begin{abstract}
Objectives: Psychiatric consequences are very common following RTA. The study is sought to identify the prevalence of psychiatric morbidity (e.g. depressive symptoms, anxiety symptoms and symptoms related to PTSD(Post Traumatic Stress Disorder) following injury sustained after road traffic accidents and to evaluate the relationship between severity of injuries of victims and psychiatric symptoms.

Methods: The 102 (male $=83$,female $=19$ ) patients were interviewed using a questionnaire to collect the socio- demographic data, the Self Rating Questionnaire (SR Q) -Beck Depression Inventory(BDI),Beck Anxiety Inventory(BAI) and the Impact of Event Scale -Revised (IES-R). Patients were prospectively followed up for 1 month. Patients were aged between 20-69 years. The impact of injury was assessed by ISS (Injury Severity Scale) and ABI (Abbreviated injury Scale).

Results:The mean age was 33.93 years (range 20-69). Overall, the prevalence rate o of Anxiety symptoms-19.6\%, depressive symptoms-21.6\% and PTSD symptoms-35.3\%. Females had a higher rate of PTSD symptoms $52.6 \%(n=10)$, compared to the males $31.3 \%$ $(n=26)$. The majority of those with PTSD (47.2\%) were young, 20 - 29 years.

The samples showed maximum symptoms of PTSD in first week $93.1 \%$ followed by depressive symptoms $51 \%$ and then anxiety symptoms $30.4 \%$. The symptoms gradually reduced in the fourth week to PTSD - 35.3\%, depression- $21.6 \%$ and anxiety-19.6\%. The study also showed higher scales of psychiatric symptoms in major injuries in comparison to minor injuries showing direct correlation of psychiatric morbidity with severity of injury.

Conclusion: P sychiatric symptoms are frequent and severe after major injuries and less severe after minor RTA. Psychopathology following injury is a frequent and persistent occurrence. Early information and advice might reduce psychological distress and symptoms.
\end{abstract}

\section{Introduction}

Motor vehicle accidents therefore are a recognized form of trauma and mental health difficulties may occur even in those who have not suffered physical injuries. $(1,2)$

Most research has focused on posttraumatic stress disorder (PTSD), with only a few studies investigating major depressive episode and anxiety. While cross-cultural and population differences undoubtedly explain some of this variance, methodological problems inherent in research with this population may also contribute to the disparate findings. ${ }^{(3)}$

Road traffic accidents are road traffic collisions involving drivers, passengers, pedestrians or cyclist. The term 'accident' erroneously suggests that all collisions are random (unpredictable) and accidental (unpreventable). ${ }^{(4)}$

Address for correspondence: namrata_mahara@yahoo.com Medical Journal of Shree Birendra Hospital
Injury is a disease resulting from an interaction of agent, host and environment. Once a person enters a health system for treatment of an injury, only then it is considered a health problem. ${ }^{(5)}$ Injury now ranks among the leading causes of morbidity and mortality world over. In fact, road traffic injury alone was ranked as the primary cause of disease among children in the age group of 5 to 14 years, and the third leading cause among people between the ages of 15 to 29 years in 2000.

There is an increasing realization that trauma can have marked and sustained psychological effects. Up to $25 \%$ of severely injured patients experience significant early psychological reactions after trauma in some patients these reactions can be long lasting and have profound adverse effects on quality of life. Those at high risk of developing thus can be identified, and effective treatment can be administered. ${ }^{(6)}$

In Nepal fall from a height accounting for the majority $(56 \%)$ compared to west where road traffic 
accident is the commonest cause males are involved twice as the females which may be because males are being exposed to the risks of accidents. ${ }^{(7)}$

The motor vehicle accidents are the single most significant event leading to the development of post traumatic stress disorder (PTSD). ${ }^{\left({ }^{8}\right)}$ P revalence of PTSD following MVA, ranges from $10 \%$ (8) to $46 \%$. ${ }^{(9)}$

In another study by ${ }^{(10)}$ reported that most of the trauma followed traffic accidents. There has been no study on psychiatric consequences of road traffic accidents in Nepal. However there are few studies related to accidents and injuries. But there are many studies in Western and European countries. In a study it is reported that in Nepal $61.5 \%$ of spinal injuries are due to traffic accidents against $45 \%$ in the world. In Nepal, the road traffic accidents are increasing day by day due to many factors like overcrowded roads, poor conditions of roads etc. (11) Thus the present study is an attempt to identify the prevalence psychiatric consequences following road traffic accidents in Nepal and with a hope that some guidelines may be developed in future for the benefit of such patients especially in consultation/liaison with other departments.

Whiplash injuries commonly occur in road traffic accidents. In this, initial acute symptoms include somatic symptoms. ${ }^{12)}$ These somatic symptoms often accompanied by psychological symptoms such as initial 'shock' 'dazed feeling, anxiety, anger. Depression, difficulty concentrating, insomnia, lassitude, loss of libido altered appetite and weight, and in some cases, feeling of helplessness horror, despair and reliving experiences. ${ }^{13)}$ In severe cases where there has been an accompanying head injury with loss of consciousness, similar disorder may occur but post traumatic stress disorders appear to be less frequent. (14) Personality changes and cognitive impairment may occur following countercoup and penetrating head injuries. ${ }^{(15)}$

Patients with posttraumatic stress disorder experience disabling memories and anxiety related to the traumatic event. Traffic accidents have become the leading cause of post-traumatic stress disorder since Vietnam War. ${ }^{(16)}$

The primary psychosocial consequences of Motor Vehicle Accidents as beyond PTSD fall into the category of psychiatric co-morbidity, with four finding emerging. First, mood disorders, especially new cases of major depression, are most common co-morbid problem: Second, study it was ${ }^{(17)}$ found that $27.4 \%$ of survivors with PTSD had another current co-morbid anxiety disorder. Third, several studies MSE a measure of 'case-ness' or sufficient symptoms on some measure to constitute a psychiatric case. Finally there is travel anxiety and driving reluctance: ${ }^{(18)}$ found that $18.4 \%$ had travel anxiety at 1 year post MVA assessment; other ${ }^{(19)}$ reported $18.2 \%$.

\section{Methods}

Patients and Procedures;This prospective cross sectional study includes 102 patients, 83 men and 19 women, mean age 33.9 years \pm (range: $20-69$ years), who were admitted at orthopedic department after injury sustained due to RTA.

After obtaining informed consent, patients were administered Semi Structured Performa in first week followed by other instrument to assess the symptoms of anxiety, depression and post traumatic stress disorder. Injury severity was assessed by administering ISS and ABI. Patients were again followed up after 4 weeks and the same scale used for the assessment. The questionnaires ask the patients to estimate their anxiety by using BAI (Beck Anxiety Inventory) (20) and depression by BDI (Beck Depression Inventory) ${ }^{(21)}$ and HIES (Horowitz's Impact of Event Scale) ${ }^{(22)}$ to explore the psychological impact of a variety of traumas. The injury severity was assessed with use of $A B I$ (Abbreviated Injury Score). (23)

Major injury caused the trauma in 55 patients and minor injury in 47 patients. Most patients had upper secondary school education ( $n-35)$, second highest had certificate level education ( $n-53)$; third had primary education ( $n$ 19), fourth had lower secondary education (n-13) and some had a university education ( $n-2)$. To compare age groups, patients were divided into 5 groups as shown in table 2.

Data about the patients participating in the study were collected and analyzed using SPPS-10 for window.

\section{Instruments}

Semi Structured Performa: Self-designed semi Structured Performa was prepared to obtain the sociodemographic characteristics of the patients. It is used to record patient's name, age, sex address, education, marital status, occupation, religion, economic status and presenting complaints.

BDI (Beck Depression Inventory): This inventory assesses depression for patient's subjective perception. The subject has to rate according to how he has been feeling during the past two weeks on a 4 point. Scale ranging from $0-3$, maximum total score is 63 . The total score is categorized into mild, moderate and severe depression. The inventory is considered as a standard scale for measuring severity of the symptoms of depression. The 21 item which are rated on a 4 point scales covers the wider Psychopathology of depression.

BAI (Beck Anxiety Inventory): $\mathrm{BAI}$ is a 21 item self 
rated questionnaire that describes common symptoms of anxiety. This scale has a reliability value of $0-92$ and a validity that ranges from $82-87$ and inventory is considered as a standard instrument to measure anxiety symptoms. Scores have implication for both in measuring severity and assessing changes in symptoms due to intervention.

IES (Horowitz's Impact of Event Scale): IES was originally developed in 1979, later it was used for exploring the psychological impact of a variety of traumas. Although many measures of PTSD symptoms have emerged ${ }^{(24)}$, the IES remains widely used. The IES does not measure the hyper arousal symptoms of PTSD described in DSM-IV ${ }^{(25)}$

Injury Severity Score (ISS): ISS is used to assesS patients in traffic accidents. It makes use of the abbreviated injury scale which is assigned a value form 1 to 6, with: Minor injury (1) Moderate injury (2) Severe but not threatening (3) Life- threatening but survival likely (4) C ritical with uncertain survival (5) Fatal (6) and its value correlates with the risk of mortality.

\section{Results}

102 patients (83 males and 19 females) were enrolled in study. The mean age was 33.93 years (range 20-69).The majority of RTA patients were male age group between $20-29(49.4 \% n=41)$ and female age group between 30-39

$(38.8 \% n=7)$. Most of the participants were married $(64.7 \% n=66)$, Hindu by religion $(88.8 \% n=90)$ and of secondary level educated $(34.3 \% n=35)$. The majority of them were service holder $(24.55 n=25)$ and from middle socio economic status $(68.6 \% \mathrm{n}=70)$.

Tables 1: Distribution of Anxiety, Depressive and PTSD symptoms in first and fourth week.

\begin{tabular}{|c|c|c|c|}
\hline \multirow{2}{*}{ Duration } & \multicolumn{2}{|c|}{ Anxiety symptoms } & \multirow{2}{*}{$x^{2}$} \\
\hline & Yes (\%) & No $(\%)$ & \\
\hline $1^{\text {st }}$ week & $31(30.4)$ & $71(69.6)$ & \multirow{2}{*}{$P=0.075$} \\
\hline $4^{\text {th }}$ week & $20(19.6)$ & $82(80.4)$ & \\
\hline \multirow{2}{*}{ Duration } & \multicolumn{2}{|c|}{ Depressive Symptoms } & \multirow{2}{*}{$x^{2}$} \\
\hline & Yes (\%) & No $(\%)$ & \\
\hline $1^{\text {st }}$ week & $52(51.0)$ & $50(49.0)$ & \multirow{3}{*}{$P=0.00001$} \\
\hline $4^{\text {th }}$ week & $22(21.6)$ & $80(78.4)$ & \\
\hline \multirow{2}{*}{ Duration } & \multicolumn{2}{|c|}{ PTSD Symptoms } & \\
\hline & Yes (\%) & No $(\%)$ & $x^{2}$ \\
\hline $1^{\text {st }}$ week & $95(93.1)$ & $7(6.9)$ & \multirow{2}{*}{$P=0.0000$} \\
\hline $4^{\text {th }}$ week & $36(35.3)$ & $66(64.7)$ & \\
\hline
\end{tabular}

Table 1:

Above shows the prevalence of anxiety, depression and PTSD in $1^{\text {st }}$ and $4^{\text {th }}$ week of patients of RTA. The anxiety symptoms in $1^{\text {st }}$ and $4^{\text {th }}$ week was significantly different $(p=0.075)$. Likewise depressive and PTSD symptoms in $1^{\text {st }}$ and $4^{\text {th }}$ was significantly different $(p=0.00001)$ and $(p=0.0000)$ respectively. 
Table 2: Symptoms distribution in first and fourth week according to Age.

\begin{tabular}{|c|c|c|c|c|c|}
\hline \multirow{3}{*}{$\begin{array}{c}\text { Age } \\
\text { (years) }\end{array}$} & \multicolumn{4}{|c|}{ Anxiety Symptoms } & \multirow{3}{*}{$p$-value } \\
\hline & \multicolumn{2}{|c|}{ First Week } & \multicolumn{2}{|c|}{ Fourth week } & \\
\hline & No $(\%)$ & Yes (\%) & No $(\%)$ & Yes (\%) & \\
\hline $20-29$ & $30(63.9)$ & $17(36.1)$ & $38(80.9)$ & $9(19.1)$ & $P=0.065$ \\
\hline $30-39$ & $18(78.2)$ & $5(21.8)$ & $20(86.9)$ & $3(13.1)$ & $P=0.699$ \\
\hline $40-49$ & $16(76.3)$ & $5(23.7)$ & $16(76.1)$ & $5(23.9)$ & $P=1$ \\
\hline $50-59$ & $5(62.5)$ & $3(37.5)$ & $6(75.0)$ & $2(25.0)$ & $P=1$ \\
\hline $60-69$ & $2(66.7)$ & $1(33.3)$ & $2(66.7)$ & $1(33.3)$ & $P=1$ \\
\hline Total & $71(69.6)$ & $31(30.4)$ & $82(80.4)$ & $20(19.6)$ & \multirow{3}{*}{ p-value } \\
\hline Age (yrs) & \multicolumn{4}{|c|}{ Depressive Symptoms } & \\
\hline $20-29$ & $19(40.5)$ & $28(59.50)$ & $32(68.1)$ & $15(31.9)$ & \\
\hline $30-39$ & $14(60.8)$ & $9(39.2)$ & $21(91.3)$ & $2(8.7)$ & $P=0.007$ \\
\hline $40-49$ & 13(61.9) & $8(38.1)$ & $18(85.7)$ & $3(14.3)$ & $P=0.038$ \\
\hline $50-59$ & $2(25.0)$ & $6(75.0)$ & $6(75.0)$ & $2(25.0)$ & $P=0.16$ \\
\hline $60-69$ & $2(66.7)$ & $1(33.7)$ & $3(100)$ & - & $P=0.132$ \\
\hline \multirow[t]{2}{*}{ Total } & $50(49.0)$ & $52(51.0)$ & $80(78.4)$ & $22(21.6)$ & $P=1.0$ \\
\hline & \multicolumn{4}{|c|}{ PTSD Symptoms } & \multirow{2}{*}{$p$-value } \\
\hline Age (yrs) & No (\%) & Yes (\%) & No (\%) & Yes (\%) & \\
\hline $20-29$ & $4(8.5)$ & $43(91.50$ & $30(63.8)$ & $17(36.2)$ & $P=0.000001$ \\
\hline $30-39$ & $1(4.3)$ & $22(95.7)$ & $16(69.6)$ & $7(30.4)$ & $P=0.00002$ \\
\hline $40-49$ & $1(4.7)$ & $20(95.2)$ & 13(61.9) & $8(38.1)$ & $P=0.0003$ \\
\hline $50-59$ & $1(1.5)$ & $7(87.5)$ & $5(62.5)$ & $3(37.5)$ & $P=0.119$ \\
\hline $60-69$ & - & $3(100)$ & $2(66.7)$ & $1(33.3)$ & $P=0.40$ \\
\hline Total & $7(6.9)$ & 95(93.1) & $66(64.7)$ & $36(35.3)$ & \\
\hline
\end{tabular}


Table 2:

Shows anxiety symptoms and depressive symptoms were not significant according to different age groups in $1^{\text {st }}$ and $4^{\text {th }}$ week. The PTSD symptoms in few of age group in $1^{\text {st }}$ and $4^{\text {th }}$ week were significant as in age group of, 20-29years $(p=0.000001), 30$-39years $(p=0.00002)$ and 40 -49years $(p=0.0003)$.

Table 3

\begin{tabular}{|c|c|c|c|}
\hline \multicolumn{4}{|c|}{ Symptoms distribution with Injury Score in First Week } \\
\hline \multirow{2}{*}{ Symptoms } & Minor Injury & Major Injury & \multirow{2}{*}{$P$ value } \\
\hline & No. $(\%)$ & No. $(\%)$ & \\
\hline Anxiety & $7(14.9)$ & $24(43.6)$ & $P=0.002$ \\
\hline Depression & $23(48.9)$ & $29(52.7)$ & $P=0.703$ \\
\hline PTSD & $47(100)$ & $48(87.3)$ & $P=0.014$ \\
\hline \multicolumn{4}{|c|}{ Symptoms distribution with Injury Score in Fourth Week } \\
\hline \multirow{2}{*}{ Symptoms } & Minor Injury & Major Injury & \multirow{2}{*}{$P$ value } \\
\hline & No. $(\%)$ & No. $(\%)$ & \\
\hline Anxiety & $4(8.5)$ & $16(29.0)$ & $P=0.018$ \\
\hline Depression & $5(10.5)$ & $17(30.9)$ & $P=0.013$ \\
\hline PTSD & $13(27.7)$ & 23(41.8) & $P=0.136$ \\
\hline
\end{tabular}

Table 3:

Shows significant difference in anxiety and PTSD symptoms in minor and major injury $(p=0.002$ and $p=$ 0.014 respectively) in $1^{\text {st }}$ week but however in $4^{\text {th }}$ week the anxiety and depressive symptoms differ significantly in minor and major injury ( $p=0.018$ and $p=0.013$ respectively). female $=10$ ).

Using the IS S patients of minor injuries were 47 (male $=38$, female $=9$ ) and major injuries were 55 ( $\mathrm{male}=45$,

Using BAI, the prevalence of anxiety in $4^{\text {th }}$ week 20 (19.6\%) was found among the patients enrolled in the study. The age of 20-29 years had maximum anxiety symptoms $(19.1 \% n=9)$ and female $(47.4 \% n=9)$ were affected more than male $(26.5 \% n=22)$.According to severity of injury anxiety predominant in major injury patients $(29 \% n=16)$ in comparison to minor injury patients $(8.5 \% \mathrm{n}=4)$.

Likewise the prevalence for depression was found to be $22(21.6 \%)$ in $4^{\text {th }}$ week. The age group affected more was $20-29(31.9 \% n=15)$ and sex affected more was female $(47.4 \% n=9)$ than male $(51.8 \% n=43)$. Depression was found more with major injury $(30.9 \% n=17)$ and less with minor injury $(10.65 n=5)$.

An overall prevalence of $35.3 \%(n=36)$ PTSD was found in $4^{\text {th }}$ week among the patients interviewed. The rate was higher among the females: 10 patients $(52.6 \%)$ met the diagnostic criteria used compared to 26 males $(31.3 \%)$ in the study. PTSD was also significantly more common among the middle aged patients. The majority, $(38.1 \%)$ of the MVA survivors were in the age group $40-49$ years. The results regarding injury severity was like anxiety and depression, the major injury having higher rates of PTDS symptoms $(41.8 \%$ $\mathrm{n}=23)$ than minor $(27.75 \mathrm{n}=13)$.

\section{Discussion}

Among those studied reflects that of the general population in that they were mostly young. The predominance of males in the sample could be easily explained. Perhaps they were more likely to be motor vehicle drivers and hence more prone to injury compared to the females. There were greater representation of married $64.7 \%$ and unmarried were $32.4 \%$. The representation of unmarried were higher in males $36.1 \%$ than females $15.8 \%$

Marriage was identified as a possible risk factor especially females, $78.9 \%$ and for the males $(64.7 \%)$ of RTA patients. Though these factors were associated with a greater risk and are similar to those of other studies on traumatic events other than motor vehicle accidents ${ }^{(26)}$ they were not statistically significant. Those with upper secondary education, professionals and students had higher rates of a c cide $n$ ts and developing psychological symptoms. An explanation for this could be that the groups more affected had greater understanding of the possible consequences of the accident and feared that their life goals and ambitions could be adversely affected.

The present study has several limitations. First, despite the fact that average number of patients 
participated in this study but there is no long-term follow-up, the decrease of post-traumatic stress during the study is a promising result. With regard to future research, it would be useful to investigate study population with a long time follow-up.

\section{Anxiety symptoms}

The study showed that the anxiety symptoms seen higher in major than in minor injury and it was significantly different $(p=0.018)$. This study also showed that the anxiety symptoms were seen higher in females than in males. The anxiety symptoms in major injury and minor injury differ significantly in different sexes. $(p=0.012)$, this may be perhaps due to vulnerability of females to any stress.

\section{Depressive Symptoms}

The study found depressive symptoms in $51.0 \%$ in first week and in the fourth week, it was found in $20.5 \%$. This study was similar to other Studies, 0 Donnell et al, 2004 showed the rates of depression following injury ranges from $5-23 \%$.

The present study found that depression was higher in age group 20-29 years and $30-39$ years in $1^{\text {st }}$ and $4^{\text {th }}$ week and were significant $(p=0.007$ and 0.038$)$ The depressive symptoms in male and female differ significantly in major and minor Injury in first week $(p=0.012)$ but did not differ significantly in $4^{\text {th }}$ week $(p=1)$.

\section{PTSD Symptoms}

In this study, self-report questionnaires were used to diagnose psychopathology in contrast to the structured clinical diagnosis. Since IES does not measure hyper- arousal symptoms, diagnosis may not be complete.

We did not use a structured diagnostic interview on identifying preexisting psychiatric pathology. It is possible that some patients suffered from mental disorders before their accident. Therefore, preexisting psychopathology cannot be excluded as an etiologic factor for the development of PTSD in this group.

Prevalence of PTSD (35.3\%) is comparable to that found in the developed countries: range $7-39 \%$. As in the other studies ${ }^{(27)}$ the females were at a greater risk of developing PTSD. Among those who developed PTSD, 38.1\% were in the age group $40-49$ years. It appears therefore that the middle aged subjects are more prone to developing PTSD than the younger and older subjects. It is possible that the older subjects had learned coping mechanisms from past experience and younger has enhance their ability to cope with new traumas. ${ }^{(28)}$ Not only has it been shown that higher age could imply a higher risk of developing post-traumatic stress symptoms, ${ }^{(29)}$ but at the same time it also has been reported that no difference concerning posttraumatic stress measured with the instrument IES could be found between younger, older and middleaged individuals. ${ }^{(30)}$ Despite the significant number of patients with PTSD none had been previously diagnosed. All were attending the clinics purely for their physical injuries. Other studies of post-traumatic stress among individuals in different age groups have shown different results.

In the present study, the IES was used to assess post- traumatic stress. This instrument has been used in previous studies of post-traumatic stress in vehicle related accidents mostly in whiplash injuries $(31,32,33$ The levels of post-traumatic stress with 102 patients suffering from moderate to severe stress symptoms in $4^{\text {th }}$ week $35.3 \%$ which were clearly higher than previously reported early after injury (13\%). (34)

Several workers ${ }^{(35,36)}$ have noted, in particular, that pre-existing major depressive disorder (MDD) and anxiety disorders were specific risk factors for developing PTSD. In the present study since the pre-existing psychiatric illness were not excluded, so specific psychiatric disorder could possibly be missed which could be associated to be of greater risk of developing PTSD. In general those who had suffered psychiatric illness in the past had a greater risk of developing PTSD. Similarly those who had other physical illnesses were at a greater risk. Perhaps the accident acted as a further stressor to these individuals who were already overwhelmed.

\section{Conclusion}

The majority of MVA survivors do develop significant rates of PTSD (35.3\%) and it is not easy to identify those at risk. A multidisciplinary approach is therefore essential in the management of the RTA survivors at the orthopedic and trauma clinics if their physical and psychological needs are to be adequately addressed.

Awareness of all the psychiatric out-comes after motor vehicle accidents, introduction of the psychological interventions that will con-tribute to the management of a very large public health problem.

Despite these limitations, the high levels of psychopathology evident in the month following the trauma indicate that psychiatric disorders frequently and persistently Co-occur following a physical injury.

Health care systems targeted at traumatically injured populations have a responsibility to adopt an evidence-based approach to early identify high-risk individuals and for early psychiatric intervention.

More important is the prevention of road traffic accidents by implementing road safety measures such as safety belts, speed limit, improved road infrastructure and strict law enforcement measures on traffic offenders which will go along way in reducing MVA and therefore PTSD and other psychiatric problems. 


\section{References}

1. O'Brien, L. S.Traumatic Events and Mental Health. University Press: Cambridge, 1998.

2. Blanchard EB, Hickling EJ, Taylor AE and Ross W R. Psychiatric morbidity associated with motor vehicle accidents. J . Nervous and Mental Disorder 1995; 183:495-504.

3. Central Bureau of Statistics. Statistical Abstract, Kenya Government Press: Nairobi, 1999.

4. Taylor S, Koch WJ, Fecteav, et al. Post traumatic stress disorder after road traffic Collisions; Patterns of response to cognitive behavior therapy. J ournal of Consulting and Clinical Psychology, 2001; 69: 541-551.

5. The ICD-10 Classification of Mental and Behavioral Disorder. Geneva: World Health Organization, 1992.

6. Alexander DA. The psychiatric consequences of trauma. Hospital Medicine, 2002; 63:12-25.

7. Sharma K. Symposium of surgical and nursing management of patients with neurotrauma. Bir Hospital, Department of Anesthesia and Neurosurgery: Nepal, 1998; 44-56.

8. MaltUF. The long term psychiatric consequences of accidental injury. British J ournal of P sychiatry. 1988; 153:554-560.

9. Blanchard EB, Hickling EJ, Taylor AE, et al. Psychological morbidity associated with motor vehicle accidents. Behavior Research and Therapy, 1994; 32:283-290.

10. Shrestha M.L, Koirala B, Vaidya P.Pancreatic resection for trauma in children. International surgical conference of society of Surgeon of Nepal, 1998; 37.

11. Statistical Pocket Book 2002: His Majesty's Government National Planning Commission Secretariat, Central Bureau of Statistics: Kathmandu, Nepal.

12. Spitzer WO, Skovron ML, Saimi LR. Scientific monograph of the Quebec task force on whiplash associated disorders: redefining 'whiplash' and its management. Spine, 1995; 20:715-735.

13. Mayou R and Radanov BP. Whiplash neck injury. J ournal of Psychosomatic medicine, 1996; 40: 461-474.

14. Mayou R, Bryant B. and Duthie R. Psychiatric consequences of road traffic accidents. British Medical J ournal, 1993; 307:647-651.

15. Lishman A. The Psychological Consequences of Cerebral Disorder. Organic P sychiatry; 1987.

16. Norris FH. Epidemiology of trauma: frequency and impact of different potentially traumatic event on different demographic groups. Journal of Consulting and Clinical Psychology, 1992; 60:409419.

17. Blanchard EB. Hickling EJ, Taylor AE, et al. Psychiatric morbidity associated with motor vehicle accidents. J ournal of Nervous and Mental Disease, 1995; 183:495-504.

18. Mayou R. Psychiatric aspects of road traffic accidents. International Review of Psychiatry, 1992; 4: 45-54.
19. Kuch K, Cox BJ, and Evans RJ, et al. (1994) Phobia, panic and pain in SS survivors of road vehicle accidents. J ournal of Anxiety Disorders, 1994; 8:181-187.

20. Beck A T, Brown G, Epstein N. and Steer RD. An inventory for measuring clinical anxiety. J ournal of Consulting and Clinical Psychology, 1988; 56: (6), 893.

21. Beck A T, Ward C H, Mendenlson M, et al. An inventory for measuring depression. Archieves of General P sychiatry, 1961; 4: 561-571.

22. Horowitz $\mathrm{MJ}$, Wilner $\mathrm{N}$, Kaltreider $\mathrm{N}$ and Alvarez W. Sigh and symptoms of post traumatic stress disorder. Archieves of General Psychiatry, 1980; 37: 85-92.

23. Greenspan L, McClellan BA. And Greig $H$. Abbreviated injury scale and injury severity score. A scoring chart. Journal of Trauma, 1985; 25:60-64.

24. Wilson AC. Assessing P sychological Traumas and PTSD. New York: Guilford Press; 1999.

25. American Psychiatric Association. Diagnostic and Statistical Manual 4th Edition (DSV-IV). Washington DC; 1994.

26. Kessler R C, Sonnega A, Bromet E J, Hughes M and Nelson C B. Posttraumatic stress disorder in the National co-morbidity survey. Arch. General Psych, 1995; 52:1048-1060.

27. Lyons J. Strategies for assessing the potential for positive adjustment following trauma. J Traumatic Stress, 1991; 4:93-111.

28. Lyons JM, McClendon OB. Changes in PTSD symptomatology as a function of aging. Nova-P sy Newsletter, 1990; 8:13-18.

29. Chung MC, Werrett J, Easthope Y, Farmer $S$. Coping with post- traumatic stress: young, middle-aged and elderly comparisons. Int J Geriatric Psychiatry, 2004; 19 : (4) 333-343

30. Kongsted A, Bendix T, Qerama E, et al. Acute stress response and recovery after whiplash injuries. A one-year prospective study. Euro J Pain, 2008; 12: (4)455-463.

31. Koopman C, Classen C, Cardena E, Spigel D. When disaster strikes, acute stress disorder may follow. J Trauma Stress, 1995; 829-46.

32. Harvey AG, Bryant RA: The relationship between acute stress disorder and posttraumatic stress disorder: a 2-year prospective evaluation. J Consult Clin Psychol, 1999; 67:985-988.

33. Shalev AY. Measuring Outcome in Posttraumatic Stress Disorder. J Clin Psychiatry, 2000; 61: (5) 33- 42.

34. Breslau N, Davis G C, Andreski P. and Peterson $E$. Traumatic events and post traumatic stress disorder in an urban population of young adults. Arch. General Psych, 1991; 48:216-222. 20.

35. Baker SP, O'Neil B, Haddon WJ, Long WB. The Injury Severity Score: a method for describing patients with multiple injuries and evaluating emergency care. J Trauma, 1974; 14:187-196.

36. Teasdale $G$, J ennett $B$. Assessment of coma and impaired consciousness: a practical scale. Lancet, 1974; 2: 81-84. 